\title{
Using Water Footprint Approaches to Estimate Water Demand in the Lake Naivasha Basin, Kenya
}

\author{
Tom Mongare Ndege \\ Department of Applied Social Sciences, Moi University \\ P.O Box 3900, Eldoret, Kenya \\ E-mail: tomndege@yahoo.com
}

Received: April 16, 2019 Accepted: November 4, 2019 Published: November 25, 2019

doi:10.5296/emsd.v9i1.15931ＵRL: https://doi.org/10.5296/emsd.v9i1.15931

\begin{abstract}
The purpose of this paper is to estimate water demand for households in Lake Naivasha basin. This is important because water demand is increasingly significant to the policy of choice for achieving sustainable water management. Realization of sustainable water use is urgent in Lake |Naivasha water basin not only because of the unstable water volumes in the Lake which have wider wellbeing effects but also because of changing land use strategies that depend on higher water abstraction. Following Mokennen,et al., (2012) this study uses a water footprint approach to estimate the responsiveness of water use choices to changes in prices and income. Data is collected using questionnaires distributed to 418 residents in the lake basin. In this paper a double log water demand function is used to estimate household water demand. This approach has the advantage of providing paramters that are easily comparable with previous studies. The paper is, however, innovative in its application of estimated "total water abstraction" using water footprint approaches. An estimated water demand elasticity of 0.347 is only significant at $p=0.01$ suggesting a weak but significant impact of water cost on water abstraction choices. These results suggest the potential of applying price/fiscal instruments to enhance sustainable water abstraction within a water stress ecosystem.
\end{abstract}

Keywords: Water footprint, Water demand, Elasticity of demand, Pricing the environment, Sustainable development

\section{Introduction}

Recognition of water as a scarce commodity spurs increasing interest in the study of water demand in recent literature. Underpinning the increased interest is the assumption that real cost water prices would endear conservative water use (Donkor et al., 2014). However, wide 
application of real cost pricing water demand methods is still quite problematic for a variety of compelling reasons: (1) Acceptability: There is still a high predilection for water to be seen as an essential commodity that should be supplied free at least for a section of the population (Garcia-Valinas et al., 2010). This objection is driven by two inter-related caveats that deal with the viability of real cost water pricing. On the one hand is the argument that water prices generated this way yield unaffordable outcomes (Garcia-Valinas, et al., 2010). On the other hand there is the complexity of enforcing real cost water pricing in developing countries (Mokennen et al., 2012; Nauges \& Whittington, 2010).

Unappreciated in this objection is the implications of free water supply particularly in water stress regions of the world. Lake Naivasha basin is located in a region where precipitation and runoff are often inadequate to maintain a sustainable water balance. This paper suggests cost effective strategies that would mitigate ecosystem collapse (MacDougall, et al., 2013) in the lake basin. Diversity is an issues that is rarely addressed in economic literature. However, as studies in ecology have demonstrated, environmental services are closely associated with the resilience that is attributable to species and genetic diversity that constitutes nature. Sustainable human activity should at least in part be informed by the conservation of nature's resilience. This paper seeks to establish how households decision impact the water ecosystem within Lake Naivasha basin.

(2) Difficulties in estimation: Evidence abounds that water demand functions are difficult to estimate. Endogeneity of prices, heterogeneity and potential of underestimating water volumes are some of the measurement challenges often discussed (Nauges \& Whittington 2010; Olmstead, et al., 2007). Studies adopt different strategies to deal with demand measurement complications. This paper adopts a novel approach to measure the quantity of water demanded. This is motivated in part by the fact that recent studies have increasingly looked at water as heterogeneous rather than homogeneous item. For example, (Mekonnen \& Hoekstra, 2011) categorizes water into green, blue and grey. According to van Noordwijk, et al., (2014) blue water is water that constitutes all forms of ground and surface water.

Conventional literature on water demand concentrate exclusively on this type of water. ( see Nauges and Whittington 2010). Recent works show that this constitutes only one third of all the water demand. As water management technology improve the use of grey water ( also known as waste water) to complement blue water is becoming increasingly significant especially in developed countries. In a stylized study, Anderson (2003) showed that water reuse has several environmental benefits including reductions in water diversion and limited water contamination. This is important in a world where global warming poses an existential threat to vast blue water resources. Greenwater, water that is contained in agricultural products and forests is the final type of water discussed in recent literature (Hoekstra and Mekonnen 2012). Underpinning this recent focus is the realization that human productivity and consumption invariably entail water abstraction. Popularly referred to as virtual water, the focus on diverse facets of water underscores the urgency of developing innovative water management strategies to engender sustainable water demand. This urgency is aggravated rather than ameliorated by the prediction of a cross-section of climate change models of increasing water scarcity. 
Following Mokennen, et al., (2012) this paper measures total water volumes related to household water footprint. Previous studies measured household blue water demand (Dalhuisen, et al., 2003; Nauges and Whittington, 2010). Whereas this may be valuable in the measurment of drinking or cooking, water, it provides inadequate results in households that have multiple water uses. Lake Naivasha basin is a classic example of an ecosystem under stress as water serves not only for domestic use but also for irrigation and waste disposal. Earlier study may thus not only have understated water values but also distorted the notion of total water value that is implied in economic theory. This study is privileged by the existence of water footrpint estimates in the lake basin ( see Mokennen et al., 2012). We adopt instrumental water price variables to control for the endogeneity problem.

And (3) Multiple water sources: Earlier studies focused on urban service water sources that entail one utility and several users (Nauges and Whittington, 2010). This scenario, however, hardly exist in developing countries. Application of water footprint approaches provides possibilities of estimating household water demand while disaggregating it into its diverse sources. This paper focuses on aggregated blue, green and grey water abstraction for housheolds in Lake Naivasha basin.

In addition, research effort on water demand is fragmented. For example, recent literature in this realm falls into two distinct areas namely economic and physical studies (e.g. Olmstead, et al., 2007; Makki et al., 2015; Nauges and Whittington, 2010; Schleich and Hilenbrand, 2009; ). Economics literature focuses to a large extent on determining the role of price on water demand at the household level (Nauges and Whittington, 2010). Physical research focuses on the physical and socioeconomic determinants of water demand (Makki et al., 2015). There is an increasing need to integrate these approaches in the face of increased water scarcity globally (Hoekstra and Mekonnen, 2012). In addition, water use efficiency which according to Keenan et al., (2013) is the ratio of water loss to carbon dioxide gain in plants provides a critical channel of using ecological systems to enrich the understanding of water demand choices at the household level.

The use of input-output concept of water productivity finds wide application in a variety disciplines. Diverse statistics generated over the five decades show that globally water productivity has significantly increased. A recent Food and Agriculture Organization (FAO) report, example, concludes that "water productivity increased at least 100 per cent between 1961 to 2001" (FAO, 2016). However, this positive assessment musks wide disperates in water application globally. There is an extensive focus on demand for blue water in recent works (Donkor et al., 2014; Makki et al., 2015). Far less effort has been dedicated to the ecological impacts of water demand intensification.

Understanding the ecosystem of suppy of water is important as the quantity and quality of water depends on lotic and lentic systems that rely on the integrity of the environment. In recent years, these systems have faced severe stress mainly because of anthropological activities that undermine ecological stability (Burkhard et al., 2012). Rapidly increasing population, rapacious depletion of natural resources, inadequate economic regulations, and use of inefficient production systems, among others have been associated with declining 
ecological services globally (Hoekstra and Mekonnen, 2012). Declining qualities of ecosystems especially its lotic and lentic sub-systems have important welbeing implications to society. This paper attempts to make a contribution in this respect by using a rarely used measure of water use in the literature to examine the potential of using market and regulatory mechanisms to realize efficient and sustainable water use in Lake Naivasha water basin area in Kenya. Recent economic development especially the rise of cut-flower farming has been shown to have significant water use implications that enhance water stress on the lake and its catchment (Mokennen et al., 2012). There is scanty knowledge on the use of economic instruments to manage water ecosystems that would guide water planning in Lake Naivasha basin. This study seeks to use a water footprint approach to develop a water demand model for the Lake Naivasha water basin.

There has been an increasing body of literature on water demand in recent years. These studies focus extensively on the management of metered water using levers of demand such as price, income, household size, and information globally (Mazzanti and Montini 2005; Nauges and Strand 2007; Nauges and Whittington, 2010). The overarching motivation in these studies is to conserve metered water by engendering its economic value through adoption of full cost water pricing. Unfortunately, much of the research effort in this respect is dominated by studies conducted in developed countries (Dalhuisen et al., 2003; Olmstead et al., 2007; Nauges and Whittington, 2010). In comparation, there is a far less focus on water demand in developing countries. This is surprising given the increasing consensus in the literature that there is increasing water stress in the latter countries. The need for development of capabilities to adapt to water stress are thus, increasingly urgent especially in the face of climate change induced water availability risks (Garten et al., 2011). This paper examines water demand in semi-arid Naiavasha basin Kenya.

Kenya is in a region that is faced with signicant water scarcity prospects that are likely to negatively impinge on her already precurious food situation. Naivasha catchment is part of the driest parts of the country that is contending with severe degradation owing to rising population and changing land use(Mokennen et al., 2012).

Extant literature shows that understanding water demand is invaluable to sustainabile water management (Hoekstra, 2007). Previous works seek to ensure both natural and financial resource sustainability (Donkor et al., 2014). Ecological sustainability is anticipated because water prices are expected to influence user choices. Water price and income elasticities are important signals in this respect. Higher water price elasticities, for example, suggest enhanced capability of prices to reduce wasteful water use and promote efficiency (Olmstead et al., 2007). Recent literature on price elasticities of water provide mixed results on the responsiveness of water demand to price changes. While some studies conclude that households face an elastic water demand (Mazzanti and Montini, 2005), others insist that the price elasticity of water is low (Olmstead et al, 2007). Thus, the extent to which prices may be used to induce conservative water use remains unresolved. This study examines water demand in semi-arid water catchment of the developing world.

Studies in urban water demand are the trail brazer of efforts to understand conservative water 
demand at the household level (Dalhuisen, et al., 2003; Donkor et al., 2014)). In this respect, there is an increasing consensus that price and income elasticity of urban water demand are important in conserving water as well as forecasting future water demand. For example, Schleich and Hilenbrand (2009) surveyed 600 water supply areas in Germany and concluded that differences in the water demand of new and old federal regions would be explained by 'current differences in price and income levels alone' (P.1756). Water demand appears to have a moderate to high responsiveness to price changes especially in developed countries where metered water is a norm. It is not clear whether these price impacts are transferrable to households that rely on unmetered water. Nauges and Whittington (2010), for example, identify three limitations to the application of the traditional water demand function to developing countries namely, incompleteness of water use data from secondary sources, heterogeneous nature of water in developing countries, and variability of access to metered water. The need for an innovative assessment of water demand in developing countries is emphasized.

\section{Review of Literature}

Extensive literature on water demand has focused on urban water demand ((Dalhuisen et al., 2003; Hoffman et al., 2010; Donkor et al., 2014). Based on the utility theory, these studies hypothesize that the price elasticity will be negative and significant. Reviews of urban water demand studies largely show that urban residential water demand is inelastic. Recent studies are driven by the need to rexamine this finding using more robust estimation techniques. Potential endogeneity problems associated with the tendency of water utilities to use block pricing which is inconsistent with the utility function is one area of concern in recent studies (Olmstead et al., 2007; Donkor et al., 2014). Olmstead et al., (2007), for instance, studied water demand in 11 urban regions in Canada and the United States and compared price elasticity under increasing block pricing system and uniform pricing system. The results show that increasing block price model is more sensitive to changes in price than uniform pricing model. The differences in demand elasticity values of increasing block pricing and uniform pricing models vanish in double log and maximum likelihood models. They generally reinforce earlier studies on urban water demand that report inelastic demand for water suggesting that prices may not be the most effective way of regulating demand. Olmstead et al. (2007), attribute the failure to achieve significantly higher elasticities to persistent data heterogeneities that linked to the water demand. They conclude that 'these models may not induce a significant break with how we think about consumer responses to non-linear water prices" (P.21). Addressing these heterogeneities probably requires fresh examination of what water demand means to end users. Recent water engineering literature increasingly underscore the heterogeneous nature of water to diverse households (Hoekstra, 2007; Naugesand Whittington,2010).

The use of water footprint rather than standard water demand in this paper is in part motivated by the increasing realization in the literature that environmental factors play a significant role in water demand (Hoffman et al., 2010; Nauges and Whittington, 2010). Hoffman et al., (2010), for example, investigated water demand in Brisbane, Australia and found that temperature and precipitation were important in determining the amount of water 
used at the household level. Focusing on a population of 950,000 residents of Brisbane, Hoffman et al., (2010)'s water demand model includes warm, rainy, and summer dummies. Using both linear and non-linear water demand models, the Hoffman and others study show that a 10 per cent increase in rainy days led to a decrease in water demand of $2.59 \%$, almost a half of the decrease associated with price of 5.88 per cent. This suggests that unlike water use planners, water users take into account ecological information in deciding their water demand choices. According to Hoffman et al., (2010), enhanced water use during non-wet days may be associated with the need to water lawns, refill swimming pools, and do gardening. The discretionary use of water associated with this activities is important because of its short and long-run impacts on water demand in urban areas. It is even more critical in developing countries where water still remains either underpriced or unpriced. Studies show that both physical and socioeconomic factors play an important role in determining water demand (Hoffman et al., 2010; Makki et al., 2015; Nauges and Whittington, 2010). There is thus, a need to gain enhanced understanding on the drivers of household water use in developing countries.

Besides households in developing countries may face distinct water demand conditions compared to those in developed countries (Nauges and Whittington, 2010). Higher levels of poverty in these countries is one reason why conventional water demand models may be inaccurate in forecasting real water use choices (Nauges and Whittington, 2010; Razafindralambo et al., 2004). Nauges and Whittington (2010), conducted an exhaustive review of water demand studies in developing countries and found that water demand in these countries was distinct from developed countries. Household's shifting dependence on a variety of water sources was one reason for this. Rather than relying on metered water as is the case with developed countries, households in developed countries draw water from diverse sources including rivers, ponds, kiosk shops, vendors, and groundwater sources. It is also possible that households make choices on water sources by taking into account qualitative aspects of water they use. Modelling of water demand under these circumstances is particularly complex. Nauges and Whittington (2010) review of studies from 1985 to 2005, concluded that three water demand models characterize the study of water demand in developing countries: (1) unconditional estimation of water demand from a specific source; (2) Discrete analysis of water demand from different sources; and (3) a combination of source choice model and water use conditional upon choice model. The diverse water demand models that are employed in developing countries are in sharp contrast with the simpler, one equation models dominant in developed countries. Econometric techniques for estimating these functions vary across studies. Nauges-Whittington's review, for example, shows that techniques choosen have varied from single demand equations, through two stage regression to a combination of a multinomial and Ordinary Least Square models. The correct specification of the technique is in large part depended on the sample size. On the other hand, a key motivation for more complex models is the need to correct for price endogeneity problems that compound the estimation of these models.

An important innovation of recent studies in water demand in developing countries is the recognition that free water as an important aspect of household choices (Nauges and Strand, 
2007). Nauges and Strand (2007) estimated water demand for non-metered residents of Central American cities and show that residents make choices not only over priced water but also non-priced water such as that provided by private water wells. Recent studies also show existence of significant virtue water that is in food and non-food production processes (Garten et al., 2011; Hoekstra and Chapagain, 2007; Ridoutti and Pfister, 2010). Riddoutti and Pfister (2010), for example, argue that water footprint is equivalent to virtue water values. In developing countries, water footprint are of great significance because of evidence that several of these countries face water scarcity. Choices of crops to grow; whether to use for irrigation, and intensities of cultivation are critical pieces of information on the sustainability of water resources. Ridoutti and Pfister (2010), show that water consumption in agri-food life cycle has important impacts on water scarcity. These impacts are rarely addressed in water demand studies.

There is a paucity of empirical data on water demand in Kenya. The few studies conducted in country yield conflicting results concerning water values and the potential of using economic instruments to promote conservative water use. For example, three land mark studies (Gulyani et al., 2005; Mokennen et al., 2012; Whittington et al., 1990) reach different conclusions concerning the viability of water markets in Kenya. Gulyani et al. (2005), concludes that prices are ineffective as an instrument of regulating water use in poor households. In a survey that was conducted in 674 households drawn from Nairobi, Kakamega, and Mombasa that sought to compare demand elasticities between poor and non-poor househoulds, Gulyani et al., (2012) found no difference in the price elasticities for water among connected and non-connected households. In constrast, other studies show that water has real value changes across income groups (Mokennen et al., 2012; Whittington et al., 1990). It is critical to understand the drivers of water demand especially among the poor who are likely to contend with enhanced water poverty in era of climate change. This paper seeks to contribute to the understanding of water management in a country with significant water stress.

\section{Methods}

This study is designed as a survey of water demand in the Lake Naivasha basin because of the need to rapidly collect pertinent data over a wide area. The study adapts the Kenya Household Budget Survey Questionnaire (KHBSQ) of 2005. KHBSQ permits collection of demographic, economic and environmental data that is critical for testing study hypotheses. An additional advantage of KHBSQ data is their ability to yield consumption rather than income statistics facilitating cross-sectional and temperol comparison of household well-being using diverse indicators. This paper focuses on water availability and use in Lake Naivasha basin.

Data reported here is drawn from a larger study conducted in 2007 that examined price and non-price conservation of water use in Lake Naivasha basin. Because of the date at which the data was collected, it has been re-examined and re-analyzed to match current trends such as price changes and population trends. Our analyses that are not reported in this paper show that price and population change may had minimal impacts on our initial results. However, 


\section{Ml Macrothink}

because we do not collect new data, we urge readers to exercise caution in interpretating the results. Nonetheless the paper's general conclusions provide important signals on water management policies and research.

The paper reports on data collected from 418 randomly selected households in two locations in Lake Naivasha basin area. Survey questionnaires were administered to 1108 households. The purpose of the survey was to estimate water demand and the budget constraint for the water demand. The survey resulted into 453 usable questionnaires translating to a return rate of 40.1 per centwhich is compareble to water demand studies in developing countries which range from 30-50 per cent Thirty five questionnaires were discarded owing to incompleteness or lack of clarity.

Descriptive and inferential statistics were used to analyze the data. Percentages, means and standard deviations aid in summarizing the data in its diverse components. An ordinary least square procedure is used to estimate the household water demand function for the basin. This is complemented by a probit function of household water scarcity perception. An F-statistic is used to test hypothesis at $\mathrm{P}=5 \%$ and $\mathrm{P}=1 \%$ two tail test.

\section{Theoretical Framework}

Following Whittington et al. (1990), this study is conceptualized as a discrete decision problem. We assume an underlying discrete utility that enable households to choose $U_{i h}$

$$
\forall n=i . j i \neq j U_{i h} \geq U_{j h}
$$

Where $U_{i, k} k=i j$, is a well defined utility function. Water demand is determined by the indirect utility

$$
U_{i k}=U(P, I, S)
$$

Where $\mathrm{S}$ is the matrix of demand shifters, $\mathrm{I}$ is a vector of household income and $\mathrm{P}$ is a vector of prices change for water abstraction from the environment. Empirically $U_{i K}$ is estimated as demand function $D_{i k}$ which we define as

$$
D_{i k}=D(P r, I n, H s, H l, H e, H f, H r, Z, \varphi)
$$

Where $\varphi$ is the normally distributed error term. $\mathrm{Z}$ is a vector of the unspecified variable that influence demand. Hr is vector of the household distance from the tarmac road. This is a proxy to household tastes that are pertinent to water use. It also measures household access to utilities. Other studies (Nauges, and Strand 2007, for example) use access to electricity as an indicator of utility availability. $\frac{\partial D}{\partial H r} \geq 0$. Hf is a vector of the distance from forests. This is used as an indicator of environmental conditions that impact on water use, $\frac{\partial D}{\partial H f} \geq 0$. He is a vector of the highest level o f education of the household head. In this study, He is used as a 
proxy of education factors that influence water use $\frac{\partial D}{\partial H e} \geq 0$. Hl is the size of land that a household owns in their current residence. This is assumed to measure potential crop life cycle water use impacts, $\frac{\partial D}{\partial H l} \geq 0$. Hs is the household size as measured by the number of members in the household, $\frac{\partial D}{\partial H S} \geq 0$. In is the vector household income, $\frac{\partial D}{\partial I n}>0 ; \frac{\partial^{2} D}{\partial I^{2}} \leq 0$. Pr is the vector of the price of water, equivalent to it marginal cost, $\frac{\partial D}{\partial P r} \leq 0$.

The cost minimization problem that faces households

$$
\operatorname{Min} C(L, K)=w L+r K \text { s.t } f(K, L)=Y ; L \geq 0 ; K \geq 0
$$

Where $C(L, K)$ is the long-run cost of water. $w$ is the wage of $L$ labor inputs. $r$ is the rent for $K$ capital inputs. The first order conditions for solving (4) are as follows:

$$
\left\{\begin{array}{c}
w=\mu^{*} f_{l}\left(k^{*} l^{*}\right) \\
r=\eta^{*} f_{k}\left(k^{*} l^{*}\right) \\
f\left(k^{*} l^{*}\right)=y^{*}
\end{array}\right.
$$

Where $\mu$ and $\eta$ are Langrage operators for minimization. We assume that households produce at the optimal level. Assuming that $\mu$ and $\eta$ are normally distributed, the optimal production plan would be expressed as:

$$
P\left(0 \leq Y^{\prime} \leq 1\right)=\left\{\begin{array}{c}
\Phi(\beta X+\varepsilon) \\
0 \text { elsewhere }
\end{array}\right.
$$

Where $Y^{\prime}$ is a probit function that takes a value of 1 when optimal production is realized and zero when households operate below the optimal level. $\beta$ is a vector of the parameters of regression. $\mathrm{X}$ is a vector of independent variables that influence household choice. $\Phi$ is the operator of a probit function.

To determine the water demand, we estimate equation (3) and equation (6) for household drawn from different part of the Lake Naivasha basin. Equation (1) provides the marginal changes in price that generate specific marginal changes in the quantity demanded of water. Equation (6) indirectly as a perception model of water scarcity

\section{Study Area}

Lake Naivasha basin is part of the eastern Rift Valley lake system that runs from the North to the south of Africa. This system of lakes is prioritized for conservation by the World Wildlife Fund because of the wealth of genetic biodiversity. Lake Naivasha is located in Kenya, about $80 \mathrm{Km}$ northeast of Nairobi. It is barely south of the equator lying $00^{\circ} 45^{\prime} \mathrm{S}$ and $360^{\circ} 20^{\prime}$. Among East Rift Valley lakes, Lake Naivasha is the most elevated at $1890 \mathrm{~m}$ above sea level. Because of it high altitude and tropical location, Lake Naivasha basin has a cool dry climate. With an average high temperature of $25^{\circ} \mathrm{C}$ and average low temperature of $9.4^{\circ} \mathrm{C}$, Naivasha 


\section{MInstitute ${ }^{\text {Mink }}$}

Environmental Management and Sustainable Development

ISSN 2164-7682

2020, Vol. 9, No. 1

basin is high hospitable through the year. Rainfall is, however, short and erratic but annual rainfall average $636 \mathrm{~mm}$.

Lake Naivasha's landmass has varied over past 100 years but the most recent estimates put it at $160 \mathrm{~km}^{2}$ (Kuhn,et al., In press). The erratic nature of prepitation in the Lake basin is the primary reason for the changing character of lake size. Depending on three critical rivers: Malewa, Gilgil and Karati, the lake draws it water from a lake basin of $3300 \mathrm{Km}^{2}$. The runoff from this basins feeds the lake system which consists of three lakes: main Lake Naivasha, a semi-separated sodic extension (Olidein Bay) and Sonachi crater. As a freshwater lake, Lake Naivasha is home to diverse fauna and flora. Recognized by the Ramsar convention as a wetland of international significance, Lake Naivasha provides critical ecosystem that support torrential and aquatic live as well as anthropogenic activity in the lake basin. Physically, however, the lake is a shallow pan that hardly exceeds 6 meters at its deepest point.

Erratic rainfall poses an existential threat to the lake. High temperature and shallow physical nature expose the lake to very high evapotranspiration. With an average annual pan evaporation of $1790 \mathrm{~mm}$, the lake is dire need of constant renewal. Such renewal depends on two sources namely lake basin runoff that is transported by rivers and local precipitation. Studies have estimated the potential of the lake's input in meeting her natural output needs (for example, Kuhn, et al., In press). The consensus in these studies is that the lake water budget is exceeding vulnerable. In a review of studies in the hydrology of the lake, Kuhn, et al., (In press) conclude that there is a high probability of natural water loss exceeding natural renewal. The significance of this vulnerability is enhanced rather than undermined by the realization that climate change models predict declining and unpredictable rainfall patterns in the lake basin. Currently highest precipitation occurs in the upper catchments where average annual rainfall is $1300 \mathrm{~mm}$ at the mountain slopes of the Abedares. Much lower rainfall readings have been recorded close to the lake with annual averages of only $650 \mathrm{~mm}$.

The stability of the lake ecosystem is severely compounded by the rise of irrigation depending horticulture and floriculture in recent years. According to Kuhn et al.,, (In press) availability of freshwater, good climatic conditions and easy access to the international market are the main drivers for the spectular rise in this industry. The importance of the horticulture/floriculture industry in Kenya cannot be overstated. Over the last two decades, floriculture and horticulture have grown to become major sources of foreign revenue contributing about 7\% of Kenya's export earning. Lake Naivasha basin produces over $96 \%$ of this output. To raise output, however, the industry has to increase its water abstraction from the water basin. Ostensibly this enhances the danger the lake's existence. The problem is compounded by the multiple use values of the lake ecosystem. Besides floriculture/horticulture, the lake supports tourism, fisheries, pastoralism and small scale agriculture in its lake basin. The diversity of activities escalates rather than reduces anthropological water footprint on the lake basin (Mokennen, et al., 2012).

In total irrigated horticulture/floriculture consists of 200 farms that vary from 1 ha to 200 ha. In total about 5025 ha of land around Lake Naivasha support horticulture/floriculture 
activities. A by-product of the horticulture/floriculture industry a rapid rise of immigrant population to the lake basin. For example, the population the horticulture/floriculture district of the lake rose by $6.6 \%$ annually from 237,902 to 551,245 in 1979 and 2009, respectively. The result is rising undeserviced communities in th district which excerbate the anthropological footprint the lake basin. Recent studies show that water demand is steadily rising not only through metered sources but also through unmetered natural source abstraction for both domestic and agricultural use. There is a dearth of knowledge on how this demand may be managed conservatively to ensure sustainability (Kuhn, In press; Mokennen,2012).

Achieving sustainable water use in lake is of great importance for the entire lake basin. Water vipor from the lake renews rain forming clouds that deliver rain to the upper catchments. These are home to small scale farms that average 2.5 ha that engage in subsistence agricultural production supporting livelihoods for a population of 1.5 million inhabitants.

Previous studies on Lake Naivasha basin have to a large extent focused on the water footprint of horticulture/floriculture farming in the basin (Kuhn et al., In press; Mokennen et al., 2012). This is not surprising given the large and unregulated abstraction of water by the industry. However, small farm activities and undeserviced urban water uses have been shown to have significant impacts. In this paper, following Makonnen et al., (2012), estimates the water footprint of different household categories in the lake basin. Unlike urban water demand studies, the paper incorporates households' demand for green and grey water to estimate water demand in lake basin. According to Mokennen et al., (2012) human water footprint consists of blue, green and grey water used annually. Blue water is water that is abstracted from the environment from surface or ground sources. Green water on the other hand is rainwater consumed while grey water is the amount of freshwater required to absolve loads of pollutants. Hoekstra, (2007) offers a detailed discussion on calculation of water footprint. This study follows Makonnen et (2012) to estimate the amount of water household require to support their socioeconomic activities.

\section{Results}

Consistent with previous water demand studies in developing countries, this study collects data on water demand, water prices, household income and other household characteristics that are pertinent to water demand. Table 1 reports on the summary statistics of these variables. 
Table 1. Descriptive Statistics of Household Water use Footprint Variables

\begin{tabular}{|l|l|l|l|l|l|}
\hline Variable & $\begin{array}{l}\text { Number of } \\
\text { Observations }\end{array}$ & Minimum & Maximum & Mean & $\begin{array}{l}\text { Standard } \\
\text { Deviation }\end{array}$ \\
\hline Water Demand $\left(000 \mathrm{~m}^{3} / \mathrm{year}\right)$ & 418 & 7.0 & 24.0 & 13.51 & 4.1 \\
\hline Price of Water (Shs//)a & 418 & 3.0 & 15.0 & 7.75 & 2.9 \\
\hline Income of Household (KShs000/yr) & 418 & 21.0 & 121.0 & 49.97 & 20.0 \\
\hline Household Size (persons) & 418 & 4 & 18 & 8.3 & 0.9 \\
\hline Household land acreage $(\mathrm{A}) \mathrm{b}$ & 418 & 2.3 & 220.5 & 18.2 & 14.2 \\
\hline House Educational attainment $(\mathrm{yrs})$ & 418 & 2.0 & 18.0 & 8.3 & 0.9 \\
\hline Household Distance from forest $(\mathrm{Km})$ & 418 & 4.0 & 43.0 & 21.3 & 1.8 \\
\hline Household Distance from road $(\mathrm{Km})$ & 418 & 1.0 & 23.0 & 8.4 & 1.6 \\
\hline
\end{tabular}

a. Shs, is the acronym for the local currency, often referred to as shillings. Using current exchange rate US\$ $1=$ Shs 100

b. Acres are used because they are the unit of choice for land size in Kenya. Ordinarily $\mathrm{Km}^{2}$ is more appropriate but acres were incorporated in the HBSQ that was used in the study.

As shown in Table 1, the quantity demanded of water varied across households. The water demands results that we report are much higher than previously estimated by other studies (Gulyani, 2005, for example). This is because of the study's focus on water footprint rather than residential water demand. Thus, water includes not only water for which household pay for through activities such as hauling, waiting or buying from vendors but also "free" water collected from private wells and water that support photosynthesis in their farmed crops. The data underscores extensive inequalities in water demand in different households. Whereas the minimum annualized water demand is $7000 \mathrm{~m}^{3}$, the maximum demand is $24000 \mathrm{~m}^{3}$. The vast difference is in part accounted for by the ecological diversity of the study area and partly to household choices. Estimation of water demand for these diverse households offers valuable insights on how price incentives may be used to induce conservative water use at the household level.

Water prices form a critical component of this study. A major problem in estimating water demand in developing countries is that of missing markets. Unlike in developed countries where water utilities use water tarriffs that reflect on water scarcity, in developing countries such tarriffs are either unavailable or incapable of effectively measuring real values of water (Nauges and Whittington, 2010). In Kenya, a vast proportion of the population depends on natural water sources including streams, ponds, rivers, and lakes for domestic and agricultural use. This study tackles this problem using surrogate markets to translate the opportunity cost of water into pecuniary values. Following Whittington et al., (1990), the study converts participants reported water acquisition efforts into water prices. As reported in Table 1, these prices varied across households. The mean water price was Sh. 7.75 per litre. This is much higher than Ksh.3.5 per litre reported in previous studies (Gulyani et al., 2005). This is a counterintuitive result. The Gulyani et al., (2005), focuses on serviced water demand.. In Kenya, serviced water is often associated with higher incomes and urbanization. Currently, many of the country's cities subsidize water through application of a block pricing 
mechanism that changes less than $\$ 0.20$ per cubic meter of water for small consumers. Though higher charges are imposed on larger consumers, these rarely exceed US \$ 0.35 per litre. Apparently when water footprint are applied in rural areas, water prices in Kenya more than double for the poor. This replicates the findings reported in other recent studies on the underserving of the poor in water supply (Kjellen \& McGranah 2006; Razafindralambo et al., 2004). Other studies raise the question of tax implications of such a loopsided water price scenario (Garcia-Valinas, MA; Martinez-Espineira, R \& Gonzalez-Gomez, F, 2010).In these study the potential retrogressive nature of current subsidies for urban households may be inferred. Notheless wide variations in water prices were obseved with the minimum price being barely a fifth of the maximum price. The former being Ksh. 3.00 (US\$ 0.03) compared with the latter which is Ksh.15 (US \$ 0.17). This difference can be explained by variations in distances households cover to water points. While some household reside near water sources, others travelled more than 5 Kilometers to the water sources. Free water sources such as personal wells also impacted on water costs to households.

Studies on urban water demand are replete with results that show that household incomes play a critical role in determining water management practices (Mazzanti et al., 2005; Olmstead et al., 2007). Unfortunately, incomes are more difficult to measure in developing countries where individuals rarely keep reliable records of their earnings. In this study, multiple indicators are used to estimate household incomes. In this respect self-reported incomes are compared with reported income sources and property values. Nonetheless, because the study does not observe annualized expenditure, these results may understate household income. In general, however, the studies offer a good estimate of household welbeing. Besides because the demand functions that are estimated in this study are non-linear, we do not expect this error to severely erode the reliability of the study findings. According to Table 1, household incomes vary in the range of Ksh 21000 to KSh. 121000 (US \$ 233.30 to US \$ 1344.00, respectively). Compared with per capita income in Kenya in 2007 which was estimated to be US \$ 846, these results reveal the study's concentration on poor households, a significant number of which depended on below poverty incomes. There is a confluence of research findings that show that such households are often confronted with severe water stress that undermine their capacity to improve their welbeing.

Estimating water demand of poor households for untapped water is important to social planner intent on improving water demand.. Household characteristics such as the level of education of household heads are important pieces of information in determining water demand. Education is important as it provides skills and attitudes that promote conservative behaviour. Besides these human capital attributes, households are also endowed with population. Studies show that the size of households is important in explaining its water demand (Hoffman et al., 2010). Large households are expected to use more water than small one for obvious reasons. The average household size in Lake Naivasha water basins was 8.3. High fertility is an important factor. Though in general Kenya's rate of population growth rate has been smoothing off since the new milleniumm, fertility still remain high especially in rural areas. According to a recent survey (Kenya, 2015), on average a woman expects to bear four children in her life time. It is critical to examine the impact of this phenomenon on 


\section{Macrothink}

access to resources. Water demand is essential not only for present welbeing but also for poisterity.

The study also includes household characteristics that previous studies rarely include in the water demand model. Part of the reason why these may have been unappreciated in previous studies is the focus on urban areas where water use is primarily an indoor activity. In some studies, however, outdoor water use is excluded through imposition of water use restrictions on outdoor activities(Fielding et al., 2013). This study focuses on the size of land because of its value in the production of crops. In Kenya, households in rural areas often maintain small farms that supply food and cash crop in support of their welbeing. In this study we estimate annualized water needs for these crops as "free" water supplied by the the global evapotranspiration system. The volume of water demand for this purpose depends in part on the size of land under cultivation. This paper uses household land size as a proxy to the land under crop cultivation. Besides land sizes the study, estimates distances of household homes from forested areas. Forests moderate temperature and precipitation through changing the flow of wind streams that are pertinent to weather changes.

Using the variables described in the foregoing paragraphs, a water demand model is estimated for the Lake Naivasha water basin. Table 2 reports on the results of this analysis.

Table 2. Non-Linear Water Demand Function

\begin{tabular}{|l|l|}
\hline Model & Double Log \\
\hline variables & Parameters \\
\hline Constant (Z) & 2.633 \\
\hline & $(0.544)^{* *}$ \\
\hline $\log P r$ & -0.347 \\
\hline & $(0.094)^{* *}$ \\
\hline $\log$ In & 0.044 \\
\hline & $(0.002)^{* *}$ \\
\hline $\log$ InSq & 0.017 \\
\hline & $(0.011)$ \\
\hline $\log \mathrm{Hs}$ & 0.007 \\
\hline & $(0.002)$ \\
\hline $\log \mathrm{Hl}$ & 0.132 \\
\hline & $(0.042)^{* *}$ \\
\hline HE & 0.027 \\
\hline & $(0.004)$ \\
\hline $\log \mathrm{Hf}$ & 0.014 \\
\hline & $(0.003)$ \\
\hline Hrd & 0.009 \\
\hline & $(0.002)$ \\
\hline Bhr & 0.258 \\
\hline & $(0.052)$ \\
\hline Wht & 0.114 \\
\hline & $(0.006)$ \\
\hline Wtr & 0.004 \\
\hline & $(0.001)$ \\
\hline Wff & 0.094 \\
\hline & $(0.011)^{*}$ \\
\hline Pr*Bhr & 0.014 \\
\hline & \\
\hline
\end{tabular}




\begin{tabular}{|l|l|}
\hline & $(0.007)^{*}$ \\
\hline Pr*wht & 0.017 \\
\hline & $(0.008)$ \\
\hline Pr*wtr & 0.013 \\
\hline & $(0.008)$ \\
\hline Pr*wff & 0.008 \\
\hline & $(0.004)$ \\
\hline R-Squared & 0.633 \\
\hline
\end{tabular}

*, significant at $\boldsymbol{\alpha}=\mathbf{0 . 0 1} * *$, significant at $\boldsymbol{\alpha}=\mathbf{0 . 0 0 5}$

Determination of household demand is important because it provides information on how price instruments may serve as incentives for conservative water use at the household level. From Table 2, the price elasticity of water is lower than unit. This suggests that increases in water prices would endear moderate changes in water use. The estimated price elasticity of 0.347 compares favorably with other studies in conducted in developing countries (Nauges and Strand 2007; Nauges and Whittington 2010). This elasticity value is not surprising. In an environment where discreationary water demand is limited, price changes may not yield huge changes in demand for water. Besides some of the price's influence on the quantity demanded is probably channeled through its interactions with household characteristics. Nonetheless, the elasticity for demand for water is significant at $\alpha=0.001$. An increase of the price by $10 \%$ leads to a $3.5 \%$ rise in the quantity demanded of water. Though this responsiveness is very low, it is likely to enhance the impact of other measures that regulate water demand such as education and bans (Mokennen et al., 2012). The value of other water regulation strategies is also supported by value of the constant of regression which at 2.56 is significant at $\mathrm{p}=0.005$. This suggests that variables that are not included in the model are significant in explaining water demand. Nonetheless, the model explains a significant part of the relationship. With R-square value of 0.63 , the model explains $63 \%$ of the model. This compare well with recent studies that have estimated the demand for water (Schleich and Hilenbrand 2009).

Theoretically households purchase water depending on their budget constraint. This is determined by their incomes. Accordingly, income elasticities are expected to be positive and strong. Income is introduced in the model as a quadratic function. From Table 2, income has a small but significant impact on water demand. As expected marginal increases in income marginally influence water demand. An icome first order income elasticity of 0.04 suggests that an increase in income of 10 percent leads to a rise water use by 0.4 per cent. Though low, this value is found to be significant. This is important because previous studies have proposed communitarian water supply rather than competitive pricing as a viable approach to achieve sustainable water management (Turpie et al., 2008). On the hand, because energy is relatively expensive for households in the developing world, higher incomes would enhance freshwater recovery from grey and green water sources.

Household characteristics are important in water demand estimation. The size of households, the size of land holdings and the level of education are included in the water demand model. Safe for household size, none of these factors appear to be important in explaining water 
demand. This underscores the superiority of water charges over other policies such as education in ensuring conservative water use in the catchments.

Households' perception of the intensity of water scarcity is also critical in choices. Households that see water as scarce are bound to assign an economic value to water than those that do not. A water scarcity function was estimated for household in the basin. The results are reported in Table 3.

Table 3. Probit Estimate of Intensity of Water Scarcity

\begin{tabular}{|l|l|l|l|l|}
\hline Variables: & Parameters & Standard & Z- & P>Z \\
\hline & & Error & value & \\
\hline DEPENDENT VARIABLE & Intensity of water & & & \\
\hline & scarcity & & & \\
\hline Dummy (l=household engages in irrigation) & $-0.517^{* *}$ & 0.158 & -1.81 & 0.002 \\
\hline Log amount of water required & $0.221^{*}$ & 0.034 & 3.423 & 0.004 \\
\hline Dummy Private Land ownership & $-0.031^{* *}$ & 0.023 & 1.63 & 0.001 \\
\hline Dummy household has borehole & $-3.062 \mathrm{E}-03$ & -0.229 & -0.23 & 0.262 \\
\hline Dummy household head suffered water related illness & $8.683 \mathrm{E}-03$ & 0.158 & 0.112 & 0.533 \\
\hline Dummy household collect water from far & $1.412 \mathrm{E}-02$ & 0.275 & 0.209 & 0.844 \\
\hline Dummy Primary School Education & $-0.682^{*}$ & 0.032 & -1.537 & 0.023 \\
\hline Dummy Household treats water & $2.638 \mathrm{E}-02$ & 0.34 & 1.743 & 0.673 \\
\hline Dummy Herders & $0.321^{*}$ & 0.012 & 1.963 & 0.002 \\
\hline Log NO. Of Rooms & $0.434^{* *}$ & 0.030 & 0.587 & 0.001 \\
\hline Log Size of Land & $6.737 \mathrm{E}-03$ & 0.176 & 2.353 & 0.969 \\
\hline Location Index & $2.437 \mathrm{E}-02)$ & 0.235 & 0.012 & 1.535 \\
\hline Constant & $-21.556^{* *}$ & 10.980 & -0.784 & 0.032 \\
\hline
\end{tabular}

Number of Observations $=418$; LRChi2 $(12)=77.58 * *$

Log likelihood $=-298.23 ; * * *$ Significant at $1 \%$ and $5 \%$ respectively

According to Table 3, water households that rely on water for irrigation have greater appreciation of water scarcity than those that do not. Increasing land use activities have enhanced the use of water for irrigation. This has enhanced the value of water among water residents in the catchment. The size of households, the amount of water that households use and attainment of primary education are also important in explaining households' perceptions.

\section{Discussion of Results}

The results of water footprint of households in Lake Naivasha basin show wide variability of water availability across households in the basin. As expected household water footrpint is positively correlated with income. High income household have a water footprint that is $30 \%$ more than their low income counterparts. This result can be explaining by two inter-related processes. First, increased incomes directly influence water footprint by enhancing purchasing power. Maximum household income was about 4 times the lowest income. Even after taking into account mandatory cost such as taxes, depreciation of capital and transcation costs, the difference in purchasing power between those who earn US \$210 and those who earn $\$ 1200$ per month is significant. Second, income has an indirect impact on water footprint 
through its influence on consumption. Cross-country studies (Hoekstra and Chapagain 2007;Hoekstra, 2007) show that countries with high incomes consume commodities that have a high water footprint compared with their low income counterparts. The jury is still out on whether this is replicated at the individual household level. However, it is possible that higher incomes lead to changes in food choices with concomitant water footprint impacts. When extended to international trade this realization create a significant condominium on production choices in developing countries. Lake Naivasha basin is a significant source flowers and fruits destined for Western European markets. The water footprint of these products are important concerns to sustainable development of the basin. The results of this paper do not resolve the issue of whether or not floriculture and horticulture industries are sustainable in Lake Naivasha basin. Such a determination would require a more indepth analysis of the industries' policies and consumer market. The results nonetheless point to environmental impacts of these industries. From the results it is clear, for example, these industries are likely to have huge water footprints on the basin.

The squared income term the OLS model yields a small and insignificant coefficient. This result flies in the face of much of popular economic theory, the Environmental Kuznets Curve(EKC) (Magnani, 2000). Proponents of EKC contend that economic growth ultimately resolve environmental degradation. Rising incomes initial deplete natural capital but subsequently enhance it through higher investment ecological friendly industries. There is no evidence from the data reported in this paper that support the inverted $u$ relationship postulated by this theory. Increased incomes do not on their own appear to reduce per capita water footprint. This result is not surprising. Literature urges caution on the use of EKC in the study of environmental degradation (Magnani, 2000; Stern, 2004). David Stern in a recent article, for example, concludes on the basis on cross-country studies that EKC has "flimsy statistical foundations". Other studies show that per capita water footprint is highest in the most wealthy nations (Hoekstra and Chapagain 2007). The results reported in this paper show that the relationship of rising water demand with rising income holds even at the household level of analysis.

The price elasticity of water that is reported in this paper is small but significant. At 0.347 , this elasticity compares favorably with price elasticities reported in urban water demand studies especially in developing countries. A $10 \%$ increase in the cost of water would reduce consumption by $3.5 \%$ - a modest but remarkable impact. Clearly the growing consensus that water conservation would at least in part be engendered by a price mechanism is relevant even in the Naivasha basin. Like other studies, however, the reprimand that the price mechanism is limited in its efficacy is irrefutable. The responsiveness of water demand to water prices changes is fairly weak.

The use of alternative strategies to enhance household water conservation motivated the analysis of data on water scarcity perception of water scarcity. Perception is used as a proxy of information about water cost. Households' inability to get adequate information on the water market is a critical weakness of the use of the water prices to estimate water demand function. Relaxing the marginal cost equals price assumption enherent in the demand function, we find that household perceptions of water scarcity are determined by a capital 
accummulation function similar to Arrow's learning-experience theory of economic growth. From the results it is clear that household assets including land, size of residence, level of education and economic activity are important in explaining their perception of water scarcity. This is not surprising from a capital accumulation perspective. Arrow's capital accumulation theory that associates social change to accumulation of learning and experience appears to be in sync with these results. In general households with high experience ( meaning accumulated assets) and new knowledge (inventions and innovations) seems to have a more accurate perception of water scarcity than those that lack these resources. The negative link between water scarcity perception and elementary education is, however, surprising. The explanation for this is probably found in the extensive time lag between school attendance and participation in the study. A significant proportion of household heads had remained out of school for more than 10 years. Our analysis of out of school period which is unreported in this paper indicated a mean value of 9.432 years. There is therefore depreciation of the human capital associated with the elementary schooling. It clear, however, that we do not adequately explain this contradictory finding using this economic argument. There is a possibility that a significant part of the answer may lie in schooling and learning processes that are beyond the scope of this paper. Suffice to say that future research should seek to dwelve into how education shapes water use choices at the household level at Lake Naivasha basin.

\section{Conclusion}

This paper estimates the water demand for Lake Naivasha basin area. Water use in the basin has drastically risen in recent years necessitating the designing of water management strategies that would ensure sustainability. Real cost water pricing provides a cost-effective strategy that remains unexplored in Lake Naivasha basin. Unlike previous studies, this paper attempts to use total water demand as indicated by household water footprints to estimate household water demand. Though this is an improvement to the water demand function based on blue water use only, it is limited in its estimation of the marginal cost of water. This is in part because of incomplete water markets. We complement the results from the water demand function with those of the house water scarcity perception. Exploiting multivariate data on household budget and capital accumulation, the paper infers on potentials for adoption of water saving strategies at the household level. The results indicate that though market based regulation of water are critical, they need to be complemented with significant investment in housing, assigning secure land property rights, education and metering of water supply. These changes have important policy implications not only in the environmental management sector but also in social development sectors.

\section{References}

Anderson, J. (2003). The environmental benefits and water recycling and reuse. Water Science and Technology: Water Supply, 3(4), 1-10. https://doi.org/10.2166/ws.2003.0041

Brown, A., \& Mattock, M. D. (2011). A review of water scarcity indices and methodologies. Fayetteville, ARK: Sustainability Consortium.

Burkhard, B., Kroll, F.,Nedkov, S., \& Muller, F. (2012). Mapping ecosystem services supply, 
demand and budgets. Ecological Indicators, 21, 17-29.

https://doi.org/10.1016/j.ecolind.2011.06.019

Cosoy, N., \& Corbera, E. (2008). Payment for ecosystem services as commodity fetishism. Ecological Economics, 69, 1228-36. https://doi.org/10.1016/j.ecolecon.2009.11.002

Dalhuisen, J. M., Florax, R. J. G. M., de Groot, H. L. F., \& Nijkamp, P. (2003). Price and income elasticities of residential water demand: a metanalysis. Land Economics, 79(2), 292-308. https://doi.org/10.2307/3146872

Donkor, E. A., Mazzuchi, T. A., Soyer, R., \& Roberson, J. (2014). Urban water demand forecasting: review of methods and models. Journal of Water Resources Planning and Management, 140(2), 146-59. https://doi.org/10.1061/(ASCE)WR.1943-5452.0000314

FAO. (2016, May 05). Unlocking the Water Potential of Agriculture. [Online] Available: http://www.fao.org/docrep/006/y4525e/y4525e06.htm

Fielding, K. S., Spinks, A., Russell, S., McCrea, R., \& Gardner, J. (2013). An experimental test of voluntary strategies to promote water management. Journal of Environmental Conservation, 114(15), 343-51. https://doi.org/10.1016/j.jenvman.2012.10.027

Garcia-Valinas, M. A., Martinez-Espineira, R., \& Gonzalez-Gomez, F. (2010). Affordability of residential water tarriffs: alternative measurment and explanation factors. Journal of Environmental Management, 91(12), 2696-706.

https://doi.org/10.1016/j.jenvman.2010.07.029

Garten, D., Heinke, J., Hoff, H., Beimans, H., Fader, M., \& Waha, K. (2011). Water availability and requirement for food production. Journal of Hydrometerology, 885-99. https://doi.org/10.1175/2011JHM1328.1

Gleeson, T., Wada, Y., \& Bierkens, M. P. P. (2012). Water balance of global aquifer revealed ground water footprint. Nature, 488, 197-200. https://doi.org/10.1038/nature11295

Gulyani, S., Tulukdar, D., \& Kariuki, R. M. (2005). Universal (non) service water market, household demand and the poor in urban Kenya. Urban Studies, 42(8), 1247-74. https://doi.org/10.1080/00420980500150557

Hoekstra, A. (2007). Human Appropriation of Natural Capital: Comparing Ecological Footprint and Water Footprint Analysis. Enschede, NL: University of Twente.

Hoekstra, A. Y., \& Chapagain, A. K. (2007). Water footprints of nations: water use by people as a function of their consumption patterns. Water Resource Management, 21, 35-48. https://doi.org/10.1007/s11269-006-9039-X

Hoekstra, A. Y., \& Mekonnen, M. M. (2012). The water footprint of humanity. Proceedings of the National Academy if Sciences of the United States of America, 109(9), 3232-7. https://doi.org/10.1073/pnas.1109936109

Hoffman, M., Worthington, A., \& Higgs, H. (2010). Urban water demand with fixed volumetric changing in a large municipality: the case of Brisbane, Australia. The Australian 
Journal of Agricultural and Resource Economics, 50, 347-59.

https://doi.org/10.1111/j.1467-8489.2006.00339.x

Keenan, T., Hollinger, D. Y., Dragoni, D., Munger, J. W., Schmid, H. P., \& Richardson, A. D. (2013). Increase in forest water-use efficiency as atmospheric carbon dioxide rise. Nature, 499, 324-27. https://doi.org/10.1038/nature12291

Kenya. (2015). Kenya Demographic and health Survey 2014. Nairobi: Government Printer.

Kjellen, M., \& McGranah, D. (2006). Informal water vendors and the urban poor,( Human Settlement Discussion Series Theme: water 3. London, UK: International Institute for Water and the Environment.

Kroll, F., Muller, F., Haase, D., \& Fohrer, N. (2012). Rural-urban gradient analysis of ecosystem services supply and demand dynamics. Land Policy, 29, 521-35. https://doi.org/10.1016/j.landusepol.2011.07.008

Kuhn, A., Britz, W., Willy, D. K., \& van Oel, P. (In press). Simulating the variability of water institutions under volatile rainfall conditions-the case of Lake Naivasha. Environmental Modelling and Software.

MacDougall, A. S., McCann, K. S., Gellner, G., \& Turkington, K. (2013). Diversity loss with persistent human disturbance increases vulnerability to ecosystem collapse. Nature, 494, 86-90. https://doi.org/10.1038/nature11869

Magnani, E. (2000). The environmental Kuznets curve, environmental protection policy and income distribution. Ecological Economics, 32(3), 431-43.

https://doi.org/10.1016/S0921-8009(99)00115-9

Makki, A. A., Stewart, R. A., Beal, C. D., \& Panuwatwanich. (2015). Novel bottom-up urban water demand forecasting model revealing the determinants, drivers and predictors of residential indoor end-user consumption. Resources, Conservation and Recycling, 95, 15-37. https://doi.org/10.1016/j.resconrec.2014.11.009

Mazzanti, M., \& Montini, A. (2005, February 01). The determinants of residential water demand: empirical evidence for a panel of Italian Municipalities.

https://doi.org/10.2139/ssrn.670234

Mekonnen, M. M., \& Hoekstra, A. Y. (2011). The green, blue and grey water footprint of crops and derived products. Hydrology and Earth System Science, 15(5), 25-29. https://doi.org/10.5194/hess-15-1577-2011

Mokennen, M. M., Hoekstra, A. Y., \& Becht, R. (2012). Mitigating the water footprint of cut flower from the Lake Naivasha Basin, Kenya. Water Resource Management, 26(13), 3725-42. https://doi.org/10.1007/s11269-012-0099-9

Nauges, C., \& Strand, J. (2007). Estimation of non-tap water demand in central American cities. Resource and Energy Economics, 29(3), 165-82.

https://doi.org/10.1016/j.reseneeco.2006.05.002 


\section{Macrothink}

Nauges, C., \& Whittington, D. (2010). Estimation of water demandin developing countries: an overview. World Bank Research Observer, 25(2), 263-94.

https://doi.org/10.1093/wbro/lkp016

Olmstead, S., Hanemann, W. M., \& Stavins, R. N. (2007). Water Demand under Alternative Price Structure: NBER Working Paper 13573. Cambridge MA: NBER.

https://doi.org/10.3386/w13573

Razafindralambo, R., Minten, B., \& Larson, B. (2004). Poverty and household water demand in Fianarantsoa, Madagascar. Oxford: Center for the Study of African Economies.

Ridoutti, B. G., \& Pfister, S. (2010). A revised approach to water footprinting to make transparent the impact of consumption and production on global freshwater scarcity. Global Environmental Change, 20(1), 113-20. https://doi.org/10.1016/j.gloenvcha.2009.08.003

Schleich, J., \& Hilenbrand, T. (2009). Determinants of residential water demand in Germany. Ecological Economics, 68(6), 1756-69. https://doi.org/10.1016/j.ecolecon.2008.11.012

Stern, D. (2004). The rise and fall of the environmental Kuznets curve. World Development, 32(8), 1419-39. https://doi.org/10.1016/j.worlddev.2004.03.004

Turpie, J. K., Marais, C., \& Blignaut, J. N. (2008). The working for water programme evolution of payments for ecosystem services mechanism that address both poverty and ecosystem services delivery. Ecological Economics, 65(4), 788-98.

https://doi.org/10.1016/j.ecolecon.2007.12.024

van Noordwijk, M., Namirembo, S., Catacutan, D., William, D., \& Gebrekirstos, A. (2014). Pricing rainbow, green, blue and grey water: tree cover and geopolitics of climatic teleconnections. Current Opinions in Environmental Sustainability, 6, 41-46.

https://doi.org/10.1016/j.cosust.2013.10.008

Whittington, D., Mu X., \& Roche, R. (1990). Calculating the value of time spent collecting water: some estimates for Ukunda, Kenya. World Development, 18(2), 269-80.

https://doi.org/10.1016/0305-750X(90)90052-Y

Zhang, C., \& Anadon, L. D. (2014). A multi-regional input-output analysis of domestic virtual water trade and provincial footprint in China. Ecological Economics, 100, 159-72. https://doi.org/10.1016/j.ecolecon.2014.02.006

\section{Copyright Disclaimer}

Copyright for this article is retained by the author(s), with first publication rights granted to the journal.

This is an open-access article distributed under the terms and conditions of the Creative Commons Attribution license (http://creativecommons.org/licenses/by/3.0/). 